\title{
OPTIMIZATION OF XYLANASE PRODUCTION BY NEWLY ISOLATED STRAIN TRICHODERMA AFROHARZIANUM ISOLATE AZ 12 IN SOLID STATE FERMENTATION USING RESPONSE SURFACE METHODOLOGY
}

\author{
ZAHRA AZZOUZ, AZZEDDINE BETTACHE, NAWEL BOUCHERBA, \\ ZAHIR AMGHAR and SAID BENALLAOUA \\ Laboratoire de Microbiologie Appliquée, Faculté des sciences de la nature et de la vie, Université de \\ Bejaia, 06000 Bejaia, Algeria. \\ $\checkmark$ Corresponding author: A. Bettache, bettache84@hotmail.fr
}

Received February 4, 2020

Xylanases are hydrolytic enzymes with wide applications in several industries, such as biofuels, paper, deinking, food and feed. Response surface methodology and Box-Behnken matrix were used to optimize the culture conditions for xylanase production by Trichoderma afroharzianum isolate AZ 12 in solid state fermentation using wheat bran as substrate. The influence of four variables was examined in this research, namely incubation time, humidity, temperature and inoculum size. The analysis of variance was applied and xylanase production was expressed with a mathematical equation as a function of the factors. The optimal conditions for xylanase production were obtained as follows: 6 days of fermentation, humidity of $85 \%$, incubation temperature of $22{ }^{\circ} \mathrm{C}$ and inoculum size of $1.9 \times 10^{7}$ spores $/ \mathrm{mL}-$ under such conditions, xylanase activity increased from 8475.87 to $14766.28 \mathrm{U} / \mathrm{mL}$. Experimental design has proven to be an effective method for determining the optimal parameters for enzyme production.

Keywords: hemicelluloses, fungus, Box-Behnken, wheat bran, fermentation

\section{INTRODUCTION}

A significant amount of hemicellulosic biomass is present in agricultural by-products. Such biomass is made up of various hemicellulosic polymers, such as xylan, mannan and galactans. Among them, xylan has drawn much interest. ${ }^{1,2}$ Complete xylan degradation requires the combined action of different xylanolitic enzymes, such as endo-xylanase, $\beta$ xylosidase, $\alpha$-arabinofuranosidase and esterase.,

Xylanase enzymes are produced by various bacteria of the Bacillus genus, ${ }^{5,6}$ fungi, such as Aspergillus and Trichoderma, ${ }^{1,7}$ and by yeasts. ${ }^{8}$ The products of xylan hydrolysis are xylose, xylobiose, xylotriose, xylotetrose and xylooligosaccharides. These compounds have possible applications as food additives for poultry, in wheat flour for improving dough handling and the quality of baked products, for extraction of coffee and plant oils, and, in combination with pectinase and cellulase, for the clarification of fruit juices and wines. ${ }^{9}$ Xylanase has been used in bleaching during paper production, resulting in reduced use of chemicals.

The optimization of culture conditions by the classical one-factor-at-a-time approach needs a considerable amount of time and work. An alternative - the statistical strategy - is to use factorial experimental design and response surface methodology (RSM), which involves a minimum number of experiments and covers a large number of factors. These methods have also been employed to improve the microbial xylanase production in solid culture. There are many reports of studies based on the application of RSM in biotechnological processes. ${ }^{10-12}$

Therefore, this study was primarily designed to optimize selected process parameters for xylanase production by a new strain of Trichoderma afroharzianum (strain AZ 12) cultivated on wheat bran, in solid fermentation, using the RSM approach. 


\section{EXPERIMENTAL}

\section{Microorganism}

Trichoderma afroharzianum isolate AZ 12 was used in this study. This strain was isolated decaying olive tree roots in the soil, in Akbou area, Bejaia, located in the north-east of Algeria. It was selected as a potent producer of xylanase and was cultured on potato dextrose agar medium at $28{ }^{\circ} \mathrm{C}$ for 7 days.

Trichoderma afroharzianum isolate AZ 12 was identified according to its morphological characteristics (septation of mycelium, shape, form, diameter and texture of spores/conidia) and the fungal spores were examined and studied using standard keys, ${ }^{13}$ combined with sequence data of their Internal Transcribed Spacer rDNA region (ITS), and genomic DNA was extracted according to Vazquez-Angulo. ${ }^{14}$ PCR amplification of ITS1-5.8S rDNA-ITS4 regions was performed by using universal primers ITS1 (5'TCCGTAGGTGAACCTGCGG-3') and ITS4 (5'TCCTCCGCTTATTGATATGC-3' $),{ }^{15}$ The PCR analysis was performed according to the method described by Gonzalez-Mendoza. ${ }^{16}$ Sequence data obtained in this study were subjected to a BLAST search of the NCBI non-redundant nucleotide database. Evolutionary analyses were performed using MEGA7 software. If the similarity of the sequence of the ITS region was more than $99 \%$ between a studied strain and its nearest neighbor, the strain concerned was considered to be the same species as its nearest neighbor.

A spore suspension (spore $/ \mathrm{mL}$ ) of Trichoderma afroharzianum isolate AZ 12 was prepared by growing this strain in PDA medium and was incubated at $28^{\circ} \mathrm{C}$ for 7 days. Then, to count the spores, they were scraped delicately, to prevent detachment of the mycelium, with a sterile scraper, adding $10 \mathrm{~mL}$ of sterile distilled water containing $1 \%$ (v/v) Tween 80 , and then collected in sterilized bottles to be used as inoculums for enzyme production. The suspension was diluted by $1: 100(\mathrm{v} / \mathrm{v})$ and the spore count was performed in a counting chamber (Malassez REF 0610610 MARIENFELD, Germany). ${ }^{17,18}$

\section{Production of xylanase}

Trichoderma afroharzianum isolate $\mathrm{AZ} 12$ was cultivated using solid state fermentation (SSF) in a 500 $\mathrm{mL}$ flask, containing wheat bran (10 g) dry substrates moistened with modified Mandels medium ${ }^{19}$ with the following composition per liter: $\mathrm{K}_{2} \mathrm{HPO}_{4} 2 \mathrm{~g}$, $\left(\mathrm{NH}_{4}\right)_{2} \mathrm{SO}_{4} 1.4 \mathrm{~g}$, urea $0.3 \mathrm{~g}, \mathrm{MgSO}_{4}\left(7 \mathrm{H}_{2} 0\right) 0.3 \mathrm{~g}$, $\mathrm{CaCl}_{2} 0.3 \mathrm{~g}, \mathrm{FeSO}_{4}\left(7 \mathrm{H}_{2} \mathrm{O}\right) 5 \mathrm{mg}, \mathrm{MnSO}_{4}\left(\mathrm{H}_{2} \mathrm{O}\right) 1.56$ $\mathrm{mg}, \mathrm{ZnSO}_{4}\left(7 \mathrm{H}_{2} \mathrm{O}\right) 1.4 \mathrm{mg}$ and $\mathrm{CoCl}_{2} 2 \mathrm{mg}$ in distilled water. The $\mathrm{pH}$ of the medium was adjusted to 5 , and it was sterilized at $121{ }^{\circ} \mathrm{C}$ for $20 \mathrm{~min}$. An inoculum (spores/g) of Trichoderma afroharzianum isolate AZ 12 was seeded in a $500 \mathrm{~mL}$ flask and incubated at deferent temperatures. Thereafter, the enzymatic extracts were harvested by crushing the contents of the flasks in $100 \mathrm{~mL}$ of distilled water with a glass rod and then shaking on an orbital shaker at $100 \mathrm{rpm}$ for 10 min at room temperature. The filtrate was centrifuged at $10000 \mathrm{~g}$ for $10 \mathrm{~min}$ at $4{ }^{\circ} \mathrm{C}$. The clear supernatant was assayed for xylanase activity and stored at $4{ }^{\circ} \mathrm{C}$ until use. ${ }^{20}$ For optimization studies, the composition of the culture medium was varied according to the experimental data, while the $\mathrm{pH}$ and source of carbon (wheat bran) were constant.

\section{Xylanase assay}

The xylanase activity was determined according to Bailey, ${ }^{21}$ using birchwood xylan (Roth, Karlsruhe, Germany) as a substrate. The liberation of reducing sugars was estimated by the dinitro-salicylic-acid (DNS) method. ${ }^{22}$ A $100 \mu \mathrm{L}$ culture supernatant was added to $900 \mu \mathrm{L}$ of xylan solution $(2 \%, \mathrm{pH} 4.8,50 \mathrm{mM}$ sodium citrate buffer) and incubated at $50{ }^{\circ} \mathrm{C}$. After 10 min, $1.5 \mathrm{~mL}$ of 3,5-dinitrosalicylic acid reagent was added to stop the reaction, and the amount of reducing sugars released in the reaction was estimated by measuring the absorbance at $540 \mathrm{~nm},{ }^{22}$ and compared to a standard curve of xylose ( 0 to $1 \mu \mathrm{mol} / \mathrm{mL})$. One unit (1 UI) of xylanase activity is defined as the amount of enzyme required to release $1 \mu \mathrm{mol}$ xylose per minute under the assay conditions.

\section{Response surface methodology}

Box-Behnken design (BBD) was selected as a suitable response surface method for optimizing the xylanase production of the solid state fermentation in order to achieve the maximal production. The incubation time $\left(\mathrm{X}_{1}\right)$, humidity $\left(\mathrm{X}_{2}\right)$, temperature $\left(\mathrm{X}_{3}\right)$ and inoculum size $\left(\mathrm{X}_{4}\right)$ were selected as independent variables. These parameters were studied at three levels: low (-1), middle (0), and high $(+1)$, whereas the amount of obtained product was defined as the response. The values of low and high levels were established by the one-factor-at-a-time approach (data not shown), and shown in Table 1.

27 experiments with 3 replicates of the central point were employed (Table 2) to fit the polynomial model based on a BBD matrix that was generated using the Design-Expert ${ }^{\circledR}$ software version 11.0.5.0 (Stat-Ease Inc.), and was conducted to optimize the processes.

For each assay, SSF employed $10 \mathrm{~g}$ of wheat bran and the initial $\mathrm{pH}$ was adjusted to 5 . The amount of moisture added to the wheat bran $\left(\mathrm{X}_{2}\right)$ (Table 1) was previously prepared by using the minimal medium. The material was uniformly distributed into $500 \mathrm{~mL}$ Erlenmeyer flasks and sterilized by autoclaving at 121 ${ }^{\circ} \mathrm{C}$ for $20 \mathrm{~min}$. When the medium reached room temperature, a suspension of deferent inoculum size (spores/g) $\left(\mathrm{X}_{4}\right)$ was spread evenly over the surface of each sample, according to the levels presented in Table 1 , and incubated for three levels of time $\left(\mathrm{X}_{1}\right)$, at different incubation temperatures $\left(\mathrm{X}_{4}\right)$, according to the predetermined levels (Table 1). Regression analysis of the data to fit a second-order polynomial equation 
(quadratic model) was carried out according to the following general equation (Eq. 1), which was, then, used to predict the optimum conditions of the extraction process:

$R=\beta_{0}+\sum_{i=1}^{n} \beta_{i} X_{i}+\sum_{i=1}^{n} \beta_{i i} X_{i}^{2}+\sum_{i=1}^{n} \sum_{j=1}^{n} \beta_{i j} X_{i} X_{j}+\varepsilon$

where $R$ represents the response surfaces, $\beta_{0}$ is the intercept term, $\beta i$ is the linear effect, $\beta i i$ is the square effect, $\beta i j$ is the interaction effect, while $X_{i}, X^{2}$ and $\mathrm{X}_{\mathrm{i}} \mathrm{X}_{\mathrm{j}}$ are linear variable, quadratic variable, and term for interaction of the variables, respectively, and " $\varepsilon$ " is the residual associated to the experiments. The surface plots were plotted by varying the values of two factors and keeping the values of other factors constant at zero level. Equation (1) was used to optimize the values of the independent parameters for the response.

\section{Statistical analysis}

The experimental results obtained by the BBD were analyzed by Design-Expert $11 \AA$ software (Version 11.0.5.0., USA). For all analyzes, the difference was considered significant when $p$-value < 0.05 for a $95 \%$ confidence interval.

\section{RESULTS AND DISCUSSION}

Biochemical and molecular characterization of Trichoderma afroharzianum strain AZ 12

Trichoderma afroharzianum isolate AZ 12 grew at $28{ }^{\circ} \mathrm{C}$ and manifested green colonies, with white cottony aerial mycelium (Fig. 1 a). Microscopic morphology entailed the analysis of zoospores, basidiospores, and sporangiospores, these spores were further stained.

Table 1

Variables and their levels for the experimental Box-Behnken design (BBD)

\begin{tabular}{lccc}
\hline \multirow{2}{*}{ Variable } & \multicolumn{3}{c}{ Coded level of variable } \\
\cline { 2 - 4 } & -1 & 0 & +1 \\
\hline Incubation time (days) & 3 & 5 & 7 \\
Humidity $(\%)$ & 55 & 70 & 85 \\
Temperature $\left({ }^{\circ} \mathrm{C}\right)$ & 22 & 26 & 30 \\
Inoculum size (spore/g) & $10^{6}$ & $10^{7}$ & $1.9 \times 10^{7}$ \\
\hline
\end{tabular}

The corneal tissue of the fungal hyphae was stained by lactophenol cotton blue dye. ${ }^{23}$ Figure $1 \mathrm{~b}$ shows this strain on lactophenol cotton blue and staining reveals septate hyphae, conidiophores very branched, irregularly whorled with ramifications at right angles, attenuated ovoid and ellipsoidal phialides at the top directly inserted on the conidiophore and green conidia, this strain was identified as Trichoderma sp.

The small subunit ribosomal RNA gene of Trichoderma afroharzianum strain AZ 12 was amplified from bulk genomic DNA by PCR and analyzed. The alignment of this ITS fragment with all related sequences in the NCBI database by the BLASTN program showed that it was identical to those of strain Trichoderma afroharzianum. The results reported in this research for the nucleotide sequence of the $5.8 \mathrm{~S}$ rRNA gene (534 bp) was deposited in the GenBank databases under accession number MT305752.

\section{Optimization of xylanase production using RSM}

RSM was used to optimize the filtered variables to improve the production of xylanase based on BBD. ${ }^{24}$ The four input variables: incubation time, humidity, temperature and inoculum size, and the response xylanase activity with respect to their 27 different trials are listed in Table 3.

\section{Analysis of real and predicted results}

According to the results obtained by the BBD matrix (Table 3), run 7 showed the highest xylanase activity $(14037.10 \mathrm{U} / \mathrm{mL})$ after 5 days of incubation at $85 \%$ humidity and $26{ }^{\circ} \mathrm{C}$, using an inoculum size of $10^{6}$ spores $/ \mathrm{g}$, while run 5 showed the minimum activity of $1461.82 \mathrm{U} / \mathrm{mL}$ of xylanase production under the following conditions: incubation period of 7 days, humidity of $70 \%$, temperature of $30{ }^{\circ} \mathrm{C}$ and inoculum size of $10^{7}$ spores/g. Ghoshal, ${ }^{25}$ Khusro, ${ }^{26}$ Bagewadi, ${ }^{27}$ Long $^{24}$ and Menezes ${ }^{28}$ confirmed the influence of optimized parameters on the xylanase production.

\section{Variance analysis for xylanolytic production (ANOVA)}

Significance of the model

ANOVA data for the model are tabulated in Table 4. This analysis demonstrated that the model is highly significant with a $p$-value of 0.0003 , while the model's $F$-value of 9.01 implies the model is significant. There is only a $0.03 \%$ chance that an $F$-value this large could occur due to noise. A $p$ value $<0.05$ is considered to be significant, ${ }^{29}$ the 
low value of the model ( $p$-value) of 0.0003 , indicating that this quadratic model is statistically significant at $95 \%$ confidence level, this means that the variables of the model have a significant effect on the $\mathrm{R}$ response.

Table2

Experimental design of BBD matrix

\begin{tabular}{lcccc}
\hline Run & Incubation time (days) & Humidity $(\%)$ & Temperature $\left({ }^{\circ} \mathrm{C}\right)$ & Inoculum size (spore/g) \\
\hline 1 & 5 & 55 & 22 & $10^{7}$ \\
2 & 5 & 70 & 22 & $10^{6}$ \\
3 & 3 & 70 & 26 & $1.9 \times 10^{7}$ \\
4 & 5 & 70 & 26 & $10^{7}$ \\
5 & 7 & 70 & 30 & $10^{7}$ \\
6 & 3 & 70 & 22 & $10^{7}$ \\
7 & 5 & 85 & 26 & $10^{6}$ \\
8 & 3 & 55 & 26 & $10^{7}$ \\
9 & 5 & 70 & 30 & $10^{6}$ \\
10 & 7 & 70 & 26 & $10^{6}$ \\
11 & 7 & 85 & 26 & $10^{7}$ \\
12 & 3 & 70 & 30 & $10^{7}$ \\
13 & 7 & 70 & 22 & $10^{7}$ \\
14 & 3 & 85 & 26 & $10^{7}$ \\
15 & 5 & 85 & 26 & $1.9 \times 10^{7}$ \\
16 & 5 & 70 & 26 & $10^{7}$ \\
17 & 5 & 70 & 22 & $1.9 \times 10^{7}$ \\
18 & 5 & 55 & 26 & $1.9 \times 10^{7}$ \\
19 & 7 & 55 & 26 & $10^{7}$ \\
20 & 5 & 55 & 26 & $10^{6}$ \\
21 & 5 & 55 & 30 & $10^{7}$ \\
22 & 5 & 85 & 22 & $10^{7}$ \\
23 & 7 & 70 & 26 & $1.9 \times 10^{7}$ \\
24 & 5 & 70 & 26 & $10^{7}$ \\
25 & 5 & 85 & 30 & $10^{7}$ \\
26 & 3 & 70 & 26 & $10^{6}$ \\
27 & 5 & 70 & 30 & $1.9 \times 10^{7}$ \\
\hline
\end{tabular}
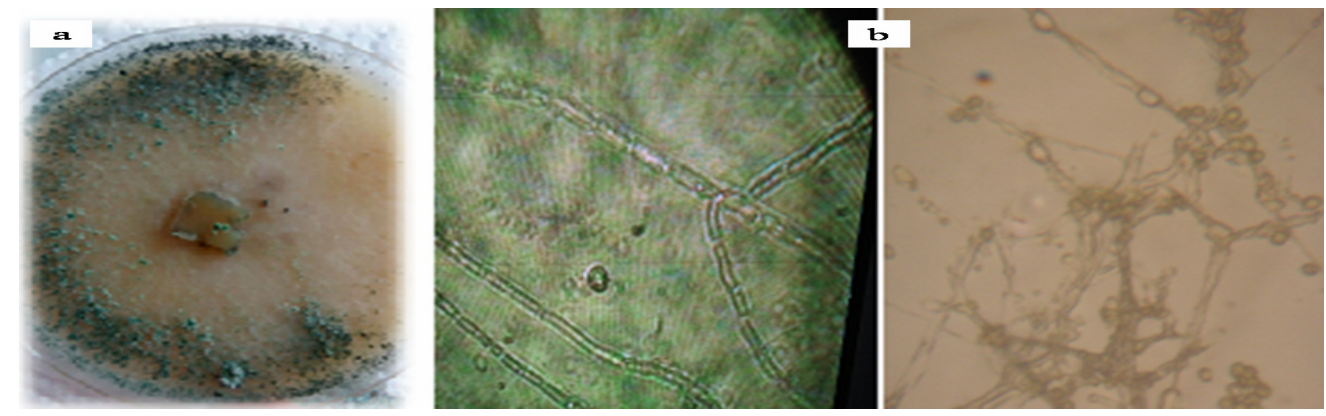

Figure 1: Morphology of Trichoderma afroharzianum strain AZ 12 obtained from roots; a) top view of the Trichoderma sp. colony in PDA; b) Microscopic morphology with lactophenol cotton blue (100x)

These results are further confirmed by the lack of fit, with an $F$-value of 16.81 , which implies there is a $5.74 \%$ chance that a lack of fit $F$-value could occur due to noise, and was not significant compared to the pure error. ${ }^{30}$ According to Bezerra, ${ }^{31}$ significant regression and a nonsignificant lack of fit present in the model was well fitted to the experiments. Based on this, the regression equation can be validated. ${ }^{32}$

\section{Determination of $\boldsymbol{R}^{2}$ coefficient}

According to Goupy, ${ }^{29} \mathrm{R}^{2}$ is a statistical parameter, which indicates the validity of the model studied. The measurement of correlation 
and the statistical significance of the model by the coefficient of determination $\mathrm{R}^{2}$ is 0.913 , close to 1 (Table 4), indicating that $91.3 \%$ of the variability of the response can be expressed by the model, which means that only $8.7 \%$ of the variability is not expressed. The $\mathrm{R}^{2}$ of the model is greater than $90 \%$, it can be seen that the model has a strong fitting ability, ${ }^{33}$ and the value of the coefficient of adjusted determination, adjusted $\mathrm{R}^{2}$, of 0.81 (Table 4) confirms that the actual values are close to the predicted values. ${ }^{34,35}$ The validation coefficient (CV) of $18.08 \%$ (Table 4) indicates that the experiments are reliable and accurate. ${ }^{26}$ All these studies reflect the accuracy and applicability of RSM. $^{34}$ This correlation was confirmed by plotting the real value curve as a function of the predicted values (Fig. 2). According to Figure 2, the points are distributed around the regression line. The model hence is considered of sufficient quality, ${ }^{35}$ there is $91.31 \%$ chance that it actually explains the measured variations in response.

Table 3

Results of real and predicted values obtained by BBD

\begin{tabular}{ccc}
\hline \multirow{2}{*}{ Run } & \multicolumn{2}{c}{ Xylanase activity, U/mL } \\
\cline { 2 - 3 } & Real values & Predicted values \\
\hline 1 & 8037.77 & 7651.71 \\
2 & 8910 & 9531.25 \\
3 & 3435.5 & 4148.94 \\
4 & 6423.96 & 6669.09 \\
5 & 1461.82 & 1005.31 \\
6 & 3925.01 & 3250.96 \\
7 & 14037.1 & 13292.66 \\
8 & 4781.09 & 5725.87 \\
9 & 6412.79 & 6454.61 \\
10 & 5869.63 & 6456.87 \\
11 & 11287.8 & 10172.87 \\
12 & 5706.46 & 3956.52 \\
13 & 6891.12 & 7510.50 \\
14 & 7166.05 & 8261.40 \\
15 & 12566.3 & 11612.08 \\
16 & 7063.23 & 6669.09 \\
17 & 7912.61 & 7700.67 \\
18 & 8232.24 & 7846.07 \\
19 & 6388.2 & 5122.74 \\
20 & 9649.36 & 9473.00 \\
21 & 5462.83 & 6732.09 \\
22 & 13393.3 & 13424.73 \\
23 & 3363.97 & 4994.22 \\
24 & 6520.08 & 6669.09 \\
25 & 6858 & 8544.73 \\
26 & 6323.38 & 5993.81 \\
27 & 5769.05 & 4977.68 \\
\hline
\end{tabular}

Table 4

Analysis of the regression model

\begin{tabular}{lccc}
\hline Source & $p$-value & $F$-value & Significance \\
\hline Model & 0.0003 & 9.01 & significant \\
Lack of fit & 0.0574 & 16.81 & not significant \\
$\mathrm{R}^{2}$ & & 0.9131 & \\
Adjusted $\mathrm{R}^{2}$ & & 0.81 & \\
$\mathrm{CV}(\%)$ & & 18.08 & \\
\hline
\end{tabular}




\section{Significance of factors effect}

\section{Linear effect}

The $p$-value of the coefficients less than 0.05 indicates that the corresponding variable is significant. ${ }^{32}$ ANOVA test applied for each factor of the culture of Trichoderma afroharzianum isolate AZ 12 showed that the linear effects, namely humidity $\left(\mathrm{X}_{2}\right)$, temperature $\left(\mathrm{X}_{3}\right)$ and the inoculum size $\left(\mathrm{X}_{4}\right)$, have a probable value of $0.0003,0.0022$ and 0.0475 , respectively (Table $5)$. They are statistically significant at $95 \%$ level of confidence, being important variables for high production of xylanases.
A higher than optimum humidity might decrease porosity and lower oxygen transfer, while a lower than optimum level might reduce solubility and the degradation of the substrate. ${ }^{36}$ Nutrient availability might also influence xylanase activity at varying humidity level. ${ }^{20,28}$ For xylanase production, different values have been reported as the optimum humidity. For instance, the optimum humidity in the production of xylanase by Aspergillus niger was $43 \%$, while this amount was $83 \%$ using Paecilomyces thermophila. ${ }^{37,38}$

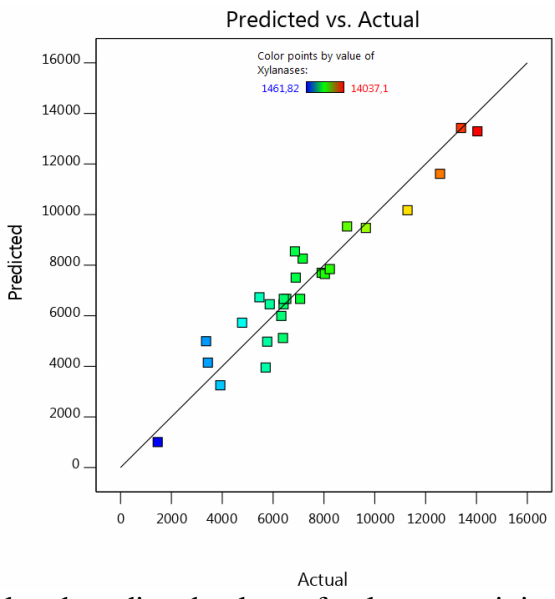

Figure 2: Correlation of actual and predicted values of xylanase activity by the response surface model

Table 5

ANOVA for response surface quadratic model (xylanase activity)

\begin{tabular}{lccc}
\hline Source & $F$-value & $p$-value & Significance \\
\hline $\mathrm{X}_{1}$-Time & 0.7622 & 0.3998 & not significant \\
$\mathrm{X}_{2}$-Humidity & 25.62 & 0.0003 & significant \\
$\mathrm{X}_{3}$-Temperature & 14.98 & 0.0022 & significant \\
$\mathrm{X}_{4}$-Inoculum size & 4.87 & 0.0475 & significant \\
$\mathrm{X}_{1} \mathrm{X}_{2}$ & 0.9385 & 0.3518 & not significant \\
$\mathrm{X}_{1} \mathrm{X}_{3}$ & 7.72 & 0.0167 & significant \\
$\mathrm{X}_{1} \mathrm{X}_{4}$ & 0.0217 & 0.8854 & not significant \\
$\mathrm{X}_{2} \mathrm{X}_{4}$ & 2.33 & 0.1530 & not significant \\
$\mathrm{X}_{2} \mathrm{X}_{4}$ & 0.0004 & 0.9839 & not significant \\
$\mathrm{X}_{3} \mathrm{X}_{4}$ & 0.0186 & 0.8939 & not significant \\
$X_{1}^{2}$ & 16.07 & 0.0017 & significant \\
$X_{2}^{2}$ & 26.71 & 0.0002 & significant \\
$X_{3}^{2}$ & 0.7458 & 0.4047 & not significant \\
$X_{4}^{2}$ & 3.06 & 0.1060 & not significant \\
\hline
\end{tabular}

Generally, humidity is an important factor affecting enzyme production. Low humidity reduces mass transfer and solubility of nutrients and increases water tension, which decreases metabolic and enzymatic activity. ${ }^{39}$ In contrast, high humidity decreases oxygen transfer and 
porosity of the medium. It also changes the structure of substrate particles and clumps the medium affecting aeration and fungal growth. ${ }^{40-42}$

Many workers have reported different temperatures for maximum xylanase production. Abdel-Sater ${ }^{43}$ screened xylan degrading filamentous fungi and reported that $T$. harzianum produced maximum xylanase at an incubation temperature of $35{ }^{\circ} \mathrm{C}$. Goyal ${ }^{44}$ reported the incubation temperature of $25{ }^{\circ} \mathrm{C}$ was best for xylanase production by $T$. viride. Fusarium oxysporum in shake flask cultures also produces maximum xylanase yield at an incubation temperature of $30{ }^{\circ} \mathrm{C}$. $\mathrm{Kuhad}^{45}$ and $\mathrm{Javed}^{46}$ showed the maximal xylanase production from isolated strains Aspergillus niger at $30{ }^{\circ} \mathrm{C}$. The optimum temperature of $40{ }^{\circ} \mathrm{C}$ was observed for xylanase production by Aspergillus niger via $\mathrm{SSF}^{47}$ These variations in incubation temperatures were due to the different nature of microorganisms and their environmental conditions. Since the fungal growth is affected by temperature, the enzyme product is dependent on temperature, but the physiological changes due to high temperatures in enzyme production are not well known. However, it is reported that high temperatures may limit the synthesis of essential proteins for fungal growth and other physiological processes. ${ }^{48-50}$

The small inoculum delays the biosynthesis of xylanases, which may be caused by the minimal presence of conidial cells, which are insufficient to use the fermentation medium in a better way. ${ }^{51,52}$ Generally, the maximum xylanase production was suggested when the inoculum size between $10^{6}$ and $10^{7}$ spores $/ \mathrm{mL} .{ }^{53}$ Previous studies by Pathak, ${ }^{54}$ Menezes ${ }^{28}$ and Abd El Aty ${ }^{55}$ on Trichoderma harzianum, Aspergillus brasiliensis and Trichoderma longibrachiatum KT693225, respectively, confirm the quote from Desai. $^{53}$

However, the incubation time impact is not significant, with a $p$-value of 0.3998 (Table 5). The results obtained are in agreement with those found by Zhang, ${ }^{56}$ Xue,${ }^{57}$ Ramanjaneyulu, ${ }^{58}$ and Yegin. ${ }^{59}$ On the other hand, Okafor ${ }^{60}$ isolated a strain of Penicillium chrysogenum PCL501 from wood wastes and reported that the highest xylanase activity of $6.47 \mathrm{U} / \mathrm{mL}$ was obtained with wheat bran after four days of fermentation. Abdel-Sater ${ }^{43}$ obtained maximum production of xylanase from Trichoderma harzianum after 8 days of fermentation. Thomas ${ }^{52}$ achieved maximum enzyme production in 4 days of fermentation by Aspergillus sp. strain and Singh ${ }^{20}$ reported maximum xylanase production of 722.98 and $228.62 \mathrm{U} / \mathrm{mL}$ for $\mathrm{SH}-1$ and $\mathrm{SH}-2$, respectively, increased up to seven days of incubation for both strains. According to Behnam, ${ }^{48}$ short cultivation times provide conditions for the production of the economical enzymes. Generally, xylanase production increased with increasing time up to a certain level and then decreased, thus, cultivation time affects xylanase production by the fungi.

\section{Interaction effect}

In order to understand the effects of different factors and their interactions on the xylanase production, the results obtained showed that the interaction between $X_{1} X_{3}$ (incubation time and temperature) has a great influence on the enzymatic activity, with a $p$-value of 0.0167 (Table 5). By contrast, no significant interaction is observed between: $X_{1} X_{2}$ (time and humidity), $\mathrm{X}_{1} \mathrm{X}_{4}$ (time and inoculum size), $\mathrm{X}_{2} \mathrm{X}_{3}$ (humidity and temperature), $\mathrm{X}_{2} \mathrm{X}_{4}$ (humidity and inoculum size), $\mathrm{X}_{3} \mathrm{X}_{4}$ (temperature and inoculum size), with $p$-values of $0.3518,0.8854,0.1530,0.9839$, 0.8939 , respectively (Table 5), which are greater than 0.05 .

The relationship between the parameters and the responses can be understood by studying the three-dimensional (3D) response surface plots for xylanase activity; this response was generated from the predicted quadratic model. The 3D response surface plot can also be used to determine the optimum level of each variable for xylanase activity (Fig. 3 A-F). While maintaining other variables at their optimal level, the Z-axis (referring to xylanase activity) versus any two variables was constructed in the response surface plot.

Figure $3 \mathrm{~A}$ illustrates combinations of the effects of independent variables on the xylanase activity. From the data obtained from the surface response graph, a tendency can be observed of the xylanase activity as a function of $\mathrm{X}_{1}$ and $\mathrm{X}_{2}$ (Fig. 3 A) - these parameters influenced insignificantly xylanase production. Behnam ${ }^{48}$ and $\mathrm{Cao}^{61}$ reported that the interaction term of moisture content and incubation time was insignificant in the optimization of xylanase production. 


\section{ZAHRA AZZOUZ et al.}
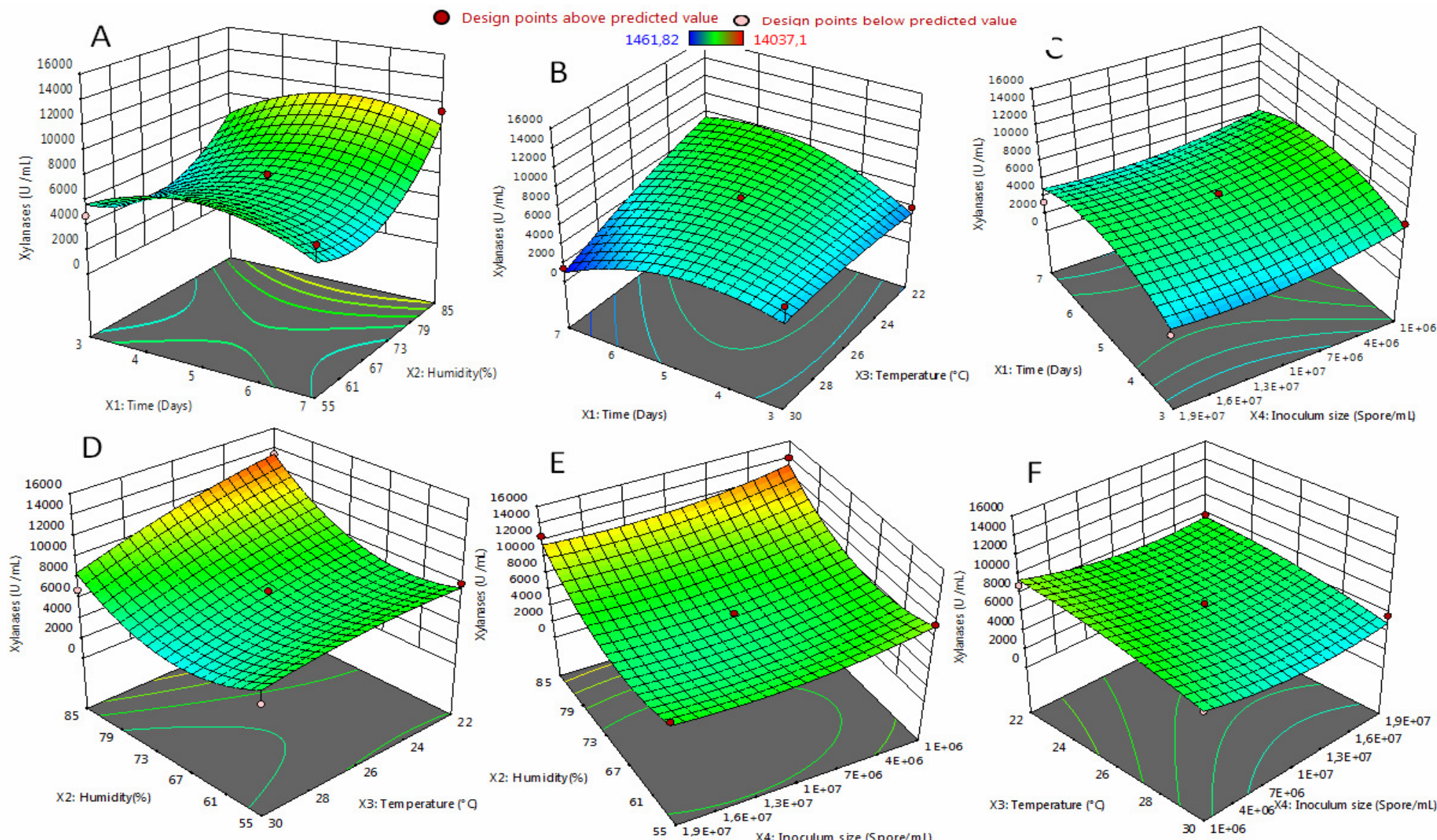

Figure 3: Response surface analysis for xylanase production by Trichoderma afroharzianum strain AZ 12 in solid state fermentation on wheat bran, with respect to incubation time and humidity (A), incubation temperature and incubation time (B), incubation time and inoculums size (C), humidity and incubation temperature (D), humidity and inoculums size (E) and incubation time and inoculums size $(\mathrm{F})$ 
Figure $3 \mathrm{~B}$ depicts the effect of $\mathrm{X}_{1}$ and $\mathrm{X}_{3}$ on the xylanase activity, when the humidity and inoculum size were fixed at level 0 . The xylanase activity increased significantly $(\mathrm{p}<0.05)$ with increasing the temperature and fermentation time, these parameters increase the xylanase activity, due to degradation of the polysaccharide molecules (xylan) present in the wheat bran by Trichoderma afroharzianum isolate AZ 12, and these two parameters may have influenced the metabolism responsible for xylanase production. The xylanase activity mainly depends on the temperature, as its quadratic and linear effects were highly significant ( $p$-value of 0.002), confirming the single-factor experiment results (Table 5). Temperature is a very significant factor in the fermentation process; high and low temperature activity may result in the reduction of microbial growth and consequently lower the production of the enzyme. According to studies conducted by Yegin, ${ }^{62}$ Dos Santos, ${ }^{63}$ Carvalho,${ }^{64}$ and Pathania, ${ }^{65}$ the interaction between incubation time and temperature have an effect on xylanase production by strains Aureobasidium pullulans Y2311-1, Aspergillus niger, and Rhizopus delemar F2, respectively. However, Behnam ${ }^{48}$ reported that the interaction term of temperature and time was insignificant in the optimization of xylanase production by strain Mucor indicus through SSF.

Figures $3 \mathrm{C}-\mathrm{F}$ show the effects of $\mathrm{X}_{1}$ and $\mathrm{X}_{4}$ (Fig. 3 C), $X_{2}$ and $X_{3}$ (Fig. 3 D), $X_{2}$ and $X_{4}$ (Fig. $3 \mathrm{E}$ ) and $X_{3}$ and $X_{4}$ (Fig. $3 F$ ) on the xylanase activity. These interactions are not significantly influenced by the response. It indicates an insignificant effect of the mutual interaction between these parameters. Behnam ${ }^{48}$ and $\mathrm{Cao}^{61}$ reported that the interaction term of humidity and incubation time was insignificant in the optimization of xylanase production. On the other hand, the studies conducted by Hanly ${ }^{66}$ reported that the interaction term of inoculum size and incubation time was significant in the optimization of xylanase and cellulase production by strain Terchoderma reesei.

\section{Quadratic effect}

Quadratic effects of $X_{1}^{2}$ (incubation time $\mathrm{x}$ incubation time) and $X_{2}^{2}$ (humidity $\mathrm{x}$ humidity) have a $p$-value of 0.0017 and 0.0002 , respectively, and are significant at $95 \%$ level. On the other hand, the terms $X_{3}^{2}$ (temperature $\mathrm{x}$ temperature) and $X_{4}^{2}$ (inoculum size $\mathrm{x}$ inoculum size) are statistically insignificant with a $p$-value of 0.4047 and 0.1060 , respectively. Previously conducted studies by Narra, ${ }^{34}$ Zhang, ${ }^{56}$ Ping $^{67}$ and Rosmine ${ }^{68}$ have found the quadratic parameters of incubation time and humidity are significant.

\section{Mathematical regression model}

The generated models were employed subsequently to study the effect of various parameters and their interactions on the xylanase activity, the model for the predicted response could be expressed by the quadratic polynomial equations (in the form of coded factors), they are excluded from the quadratic polynomial equation of the model. ${ }^{27,68}$ The simplified model is given by Equation (2) in terms of coded factors and can be used to make predictions about the response for given levels of each factor. The coded equation is useful for identifying the relative impact of the factors by comparing the factor coefficients.

$R=6669.09+327.08 X_{1}+180601 X_{2}-1529.25 X_{3}-815.85 X_{4}+62865 X_{1} X_{2}-180269 X_{1} X_{3}$ $+95.55 X_{1} X_{4}-807.47 X_{2} X_{3}-13.41 X_{2} X_{4}+55.32 X_{3} X_{4}-227.85 X_{1}^{2}+290.95 X_{2}^{2}-435.49 X_{3}^{2}$ $+91083 X_{4}^{2}$

where $\mathrm{R}$ is the xylanase activity, $\mathrm{X}_{1}$ is incubation time, $X_{2}$ is humidity, $X_{3}$ is incubation temperature and $X_{4}$ is inoculum size. The positive sign in front of the terms indicates a synergistic effect, whereas the negative sign indicates an antagonistic effect on the xylanase enzyme product.

Table 6

Optimal conditions for xylanase production proposed by BBD model

\begin{tabular}{ccccccc}
\hline Tests & $\begin{array}{c}\text { Time } \\
(\text { days })\end{array}$ & $\begin{array}{c}\text { Humidity } \\
(\%)\end{array}$ & $\begin{array}{c}\text { Temperature } \\
\left({ }^{\circ} \mathrm{C}\right)\end{array}$ & $\begin{array}{c}\text { Inoculum size } \\
(\text { spore } / \mathrm{g})\end{array}$ & $\begin{array}{c}\text { Predicted values } \\
(\mathrm{U} / \mathrm{mL})\end{array}$ & $\begin{array}{c}\text { Real values } \\
(\mathrm{U} / \mathrm{mL})\end{array}$ \\
\hline 1 & 5 & 85 & 29 & $1.6 \times 10^{7}$ & 9392.63 & 1355.09 \\
2 & 6 & 85 & 22 & $1.9 \times 10^{7}$ & 14114.87 & 14766.28 \\
3 & 7 & 85 & 22 & $1.9 \times 10^{7}$ & 14038.99 & 13352.52 \\
\hline
\end{tabular}




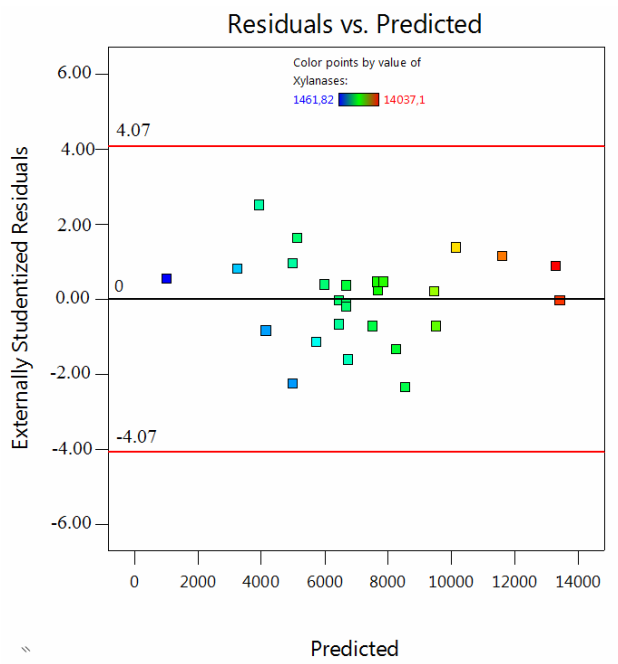

Figure 4: A residual plot for xylanase activity obtained by RSM

\section{Model validation}

Response surface equations were validated by the contrast between the experimental values and the estimated values derived from the response regression. The final step of the RSM after selecting the optimum parameter combination is to predict and verify the improvement of the performance characteristics with the selected optimum parameters. In this work, after determining the optimum conditions and predicting the response under these conditions, a new set of experiment was designed and conducted with the selected optimal conditions to predict and verify the accuracy of the mathematical model. A new range and level of the variables were studied in order to further determine the maximum xylanase production at different variable levels. The ranges of variable levels were set up based on the maximum production of xylanase recorded in the full model. The ranges of values used are shown in Table 6. The analysis of residuals appears to be a very useful and remarkably simple tool in model building and model criticism. Residuals play an important role in judging model adequacy. The residuals from the regression model are shown in Figure 4, which presents plot residuals versus the predicted response. A random pattern on these plots would indicate model adequacy.

The optimal conditions proposed by the BBD model for xylanase activity are shown in Table 6 . The optimal xylanase production of 14766.28 $\mathrm{U} / \mathrm{mL}$ was noted for test $\mathrm{n}^{\circ} 2$ under the following conditions: 6 days of incubation, $85 \%$ humidity, incubation temperature of $22{ }^{\circ} \mathrm{C}$ and inoculum size of $1.9 \times 10^{7}$ spores/g.

\section{CONCLUSION}

The current study elucidates potential xylanase production using wheat bran as economical carbon source by Trichoderma afroharzianum isolate AZ 12 in solid state fermentation. The statistical optimization method for the fermentation process can overcome the limitations of the classic empirical methods and proved to be a powerful tool for the optimization of xylanase production. The influences of different operating parameters (incubation time, humidity, incubation temperature and inoculum size) on xylanase production were studied by Box-Behnken matrixbased RSM. The study of 3D plots and ANOVA analysis of the quadratic model showed that the optimum xylanase production by Trichoderma afroharzianum strain AZ 12, employing wheat bran as solid substrate, was recorded at 14766.28 $\mathrm{U} / \mathrm{mL}$, for the following parameters of SSF: incubation temperature at $22{ }^{\circ} \mathrm{C}, 84 \%$ humidity, 6 days of fermentation and inoculum size of 1.9 $\mathrm{x} 10^{7} \quad$ spore/g. The applied second-order polynomial model gave a satisfactory description of the experimental data; it showed that the efficiency of xylanase activity was affected by the forth studied parameter. RSM was established to be more satisfactory and effective than other methods, due to its efficacy in studying many variables simultaneously, with a low number of experiments, saving time and costs.

\section{REFERENCES}

1 S. Shrivastava, V. Kumar, M. Baweja and P. Shukla, J. Pure Appl. Microbiol., 10, 2225 (2016), https://go.gale.com/ps/i.do?id=GALE\%7CA48165035 
$3 \&$ sid $=$ googleScholar $\& v=2.1 \& i t=$ $\mathrm{r} \&$ linkaccess $=\mathrm{abs} \& \mathrm{issn}=09737510 \& \mathrm{p}=\mathrm{AONE} \& \mathrm{sw}=\mathrm{w}$

2 M. Basu, V. Kumar and P. Shukla, Curr. Protein Pept. Sci., $\quad 19, \quad 87 \quad$ (2018), http://dx.doi.org/10.2174/13892037186661611221102 00

3 S. Subramaniyan and P. Prema, Crit. Rev. Biotechnol., $\quad 22, \quad 33 \quad$ (2002), https://doi.org/10.1080/07388550290789450

4 T. Collins, C. Gerday and G. Feller, FEMS Microbiol. Rev., 29, 3 (2005), https://doi.org/10.1016/j.femsre.2004.06.005

C. Azeri, U. A. Tamer and M. Oskay, African J. Biotechnol., $\quad 9, \quad 63 \quad$ (2010) https://www.ajol.info/index.php/ajb/article/view/77769 6 B. Battan, J. Sharma, S. S. Dhiman and R. C. Kuhad, Enzyme Microb. Technol., 41, 733 (2007), https://doi.org/10.1016/j.enzmictec.2007.06.006

S. Kumar, N. Sharma and S. Pathania, Cellulose Chem. Technol., 51, $403 \quad$ (2017), http://www.cellulosechemtechnol.ro/pdf/CCT56(2017)/p.403-415.pdf

8 V. Lombard, H. Golaconda Ramulu, E. Drula, P. M. Coutinho and B. Henrissat, Nucleic Acid. Res., 42, 490 (2013), https://doi.org/10.1093/nar/gkt1178

9 P. Shukla, in "Frontier Discoveries and Innovations in Interdisciplinary Microbiology", edited by V. Kumar and P. Shukla, Springer, New Delhi, 2015, pp. 157-165, https://doi.org/10.1007/978-81-322-2610-9_9

10 M. B. Limkar, S. V. Pawar and V. K. Rathod, Biocatal. Agric. Biotechnol., 17, 455 (2019), https://doi.org/10.1016/j.bcab.2018.12.008

11 U. R. Ezeilo, R. A. Wahab and N. A. Mahat, Renew. Energ., in press, (2019), https://doi.org/10.1016/j.renene.2019.11.149

12 F. Yan, W. Lei, K. Ajab, Z. Rui, W. Siang et al., Poult. Sci., 99, 263 (2020), https://doi.org/10.3382/ps/pez482

13 H. L. Barnett, and B. B. Hunter, "Illustrated Genera of Imperfect Fungi", Burgers Publishing Company, Minneapolis, Minnesota, USA, 1972, pp. 241

14 J. C. Vazquez-Angulo, V. Mendez-Trujillo, D. González-Mendoza and A. Morales-Trejo, Genet. Mol. Res., $\quad 11, \quad 1379 \quad$ (2012), http://dx.doi.org/10.4238/2012.May.15.8

15 T. J White, T. Bruns, S Lee and J. Taylor, "PCR Protocols: A Guide to Methods and Applications", Academic Press, San Diego, 1990, pp. 315-322, https://www.researchgate.net/publication/223397588

16 D. Gonzalez-Mendoza, A. Q. Moreno and O. Zapata-Perez, Zeitschrift fur Naturforsch C, 63, 124 (2008), https://doi.org/10.1515/znc-2008-1-222

17 C. L. Handa, U. R. Couto, A. H. Vicensoti S. R. Georgetti and E. I. Ida, Food Chem., 152, 56 (2014), http://dx.doi.org/10.1016/j.foodchem.2013.11.101

18 S. K. Ang, A. Yahya, S. A. Aziz and M. Salleh, Prep. Biochem. Biotechnol., 45, 279 (2015), https://doi.org/10.1080/10826068.2014.923443
19 M. Mandels and J. Weber, Food Microbiol., 23, $391 \quad$ (1969), https://doi.org/10.1021/ba-19690095.ch023

20 S. Singh, C. H. Tyagi, D. Dutt and J. S. Upadhyaya, New Biotechnol,, 26, 4 (2009), https://doi.org/10.1016/j.nbt.2009.09.004

21 M. J. Bailey, P. Biely and P. Kaisa, J. Biotechnol., 23, 257 (1992), https://doi.org/10.1016/01681656 (92) $90074-\mathrm{j}$

22 G. L. Miller, Anal. Chem., 31, 426 (1959), https://doi.org/10.1021/ac60147a030

23 D. Talukdar, R. Sharma, S. Jaglan, R. Vats, R. Kumar et al., Environ. Technol. Innov., 17, 100604 (2020), https://doi.org/10.1016/j.eti.2020.100604

24 C. Long, J. Liu, L. Gan, B. Zeng and M. Long, Waste Biomass Valor., 10, 1277 (2019), https://doi.org/10.1007/s12649-017-0149-x

25 G. Ghoshal, U. C. Banerjee and U. S. Shivhare, J. Biochem. Tech., 6, $1013 \quad$ (2016), https://jbiochemtech.com/storage/models/article/FxtS9 ecEME67kAMKR8qidsrs5a1b6tn8yttuS0bfPiYpTxP7 zaMSVfTUfCPt/utilization-of-agrowaste-andxylanase-production-in-solid-state-fermentation.pdf ${ }^{26}$ A. Khusro, B. K. Kaliyan, N. A. Al-Dhabi, M. V. Arasu and P. Agastian, Electron. J. Biotechnol., 22, 16 (2016), https://doi.org/10.1016/j.ejbt.2016.04.002

27 Z. K. Bagewadi, S. I. Mulla, Y. Shouche and H. Z. Ninnekar, 3 Biotech, 6, 164 (2016), https://doi.org/10.1007/s13205-016-0484-9

28 S. Menezes, D. M. Rossi, F. Squina and A. Z. A. Marco, Int. J. Food Sci. Technol., 53, 2110 (2018), https://doi.org/10.1111/ijfs.13798

29 J. Goupy, Rev. Stat. Appl., 38, 5 (1990), http://www.numdam.org/item/RSA_1990_38_4_5_0/ 30 M. Peña-Maravilla, M. Calixto-Romo, K. GuilllénNavarro, J. Sánchez and L. Amaya-Delgado, Rev. Mex. Anal. Conducta, 16, $757 \quad$ (2017), http://www.redalyc.org/articulo.oa?id=62053304006.

31 M. A. Bezerra, R. E. Santelli, E. P. Oliveira, L. S. Villar and L. A. Escaleira, Talanta, 76, 965 (2008), https://doi.org/10.1016/j.talanta.2008.05.019

32 X. He, C. Song, Y. Li, N. Wang, L. Xu et al., Ecotoxicol. Environ. Saf., 150, 232 (2018), https://doi.org/10.1016/j.ecoenv.2017.12.043

33 Y. Xie, P. Hu, N. Zhu, F. Lei, L. Xing et al., Renew. Energ., 147, $249 \quad$ (2020), https://doi.org/10.1016/j.renene.2019.08.109

34 M. Narra, G. Dixit, J. Divecha, K. Kumar, D. Madamwar et al., Int. Biodeter. Biodegrad., 88, 150 (2014), https://doi.org/10.1016/j.ibiod.2013.12.016

35 G. Coman and G. Bahrim, Ann. Microbiol., 61, 773 (2011), https://doi.org/10.1007/s13213-0100195-0

36 M. Raimbault and D. Alazard, Eur. J. Appl. Microbiol. Biotechnol., 9, $199 \quad$ (1980), https://doi.org/10.1007/BF00504486

37 P. P. Kheng and I. C. Omar, J. Sci. Technol., 27, 325 (2005), https://rdo.psu.ac.th/sjstweb/journal/272/10xylanase.pdf 
38 S. Q. Yang, Q. J. Yan, Z. Q. Jiang, L. T. Li, H. M. Tian et al., Bioresour. Technol., 97, 1794 (2006), https://doi.org/10.1016/j.biortech.2005.09.007

39 A. K. Bharti, A. Kumar, A. Kumar and D. Dutt, $J$. Radiat. Res. Appl. Sci., 11, 271 (2018), https://doi.org/10.1016/j.jrras.2018.01.003

40 K. Adinarayana, P. Ellaiah, B. Srini, R. Bha and G. Adinarayana, Process Biochem., 38, 1565 (2003), https://doi.org/10.1016/S0032-9592(03)00057-8

${ }^{41}$ X. Wang, J. Bai and Y. Liang, Appl. Microbiol. Biotechnol., $\quad \mathbf{7 3}, \quad 533 \quad$ (2006), https://doi.org/10.1007/s00253-006-0496-1

42 M. Khanahmadi, I. Arezi, M. Amiri and M. Miranzadeh, Biocatal. Agric. Biotechnol., 13, 272 (2018), https://doi.org/10.1016/j.bcab.2018.01.005

43 M. A. Abdel-Sater and A. H. M. El-Said, Int. Biodeter. Biodegrad., 47, $15 \quad$ (2001), https://doi.org/10.1016/S0964-8305(00)00113-X

44 M. Goyal, K. L. Kalra, V. K. Sareen, and G. Soni, Brazilian J. Microbiol., 39, $535 \quad$ (2008), https://doi.org/10.1590/S1517-83822008000300025

45 R. C. Kuhad, M. Manchanda and A. Singh, Process Biochem., 33, 641 https://doi.org/10.1016/S0032-9592(98)00025-9 46 U. Javed, A. Aman, S. Ali and U. Qader, Bioresour. Bioprocess., 4, 1 (2017), https://doi.org/10.1186/s40643-017-0149-5

47 A. Pal and F. Khanum, Bioresour. Bioprocess., 101 7563

(2010),

https://doi.org/10.1016/j.biortech.2010.04.033

48 S. Behnam, K. Karimi, M. Khanahmadi and Z. Salimian, Biol. J. Microorg., 4, 1 (2016), https://www.sid.ir/en/journal/ViewPaper.aspx?ID=509 316

49 S. A. D. Harris and C. Ramalingam, Asian J. $\begin{array}{llll}\text { Pharm., } & \text { 9, } & 50 & \text { (2016), }\end{array}$ https://dx.doi.org/10.22377/ajp.v10i1.551

50 P. Kumar, B. Ryan and G. T. M. Henehan, Protein $\begin{array}{llll}\text { Expr. } & \text { Purif., } & \text { 132, } & 164 \quad \text { (2017), }\end{array}$ https://doi.org/10.1016/j.pep.2017.01.011

51 N. Bansal, R. Tewari, R. Soni and S. Kumar, Waste Manag., $\quad 32, \quad 1341 \quad$ (2012), https://doi.org/10.1016/j.wasman.2012.03.006

52 L. Thomas, B. Parameswaran and A. Pandey, Renew. Energ., 98, 9 (2016), https://doi.org/10.1016/j.renene.2016.05.011

53 D. I. Desai and B. D. Iyer, Waste Biomass Valor., 8, 103 (2016), https://doi.org/10.1007/s12649-0169567-4
54 P. Pathak, N. K. Bhardwaj and A. K. Singh, Appl. Biochem. Biotechnol., 172, $3776 \quad$ (2014), https://doi.org/10.1007/s12010-014-0758-9

55 A. A. Abd El Aty, S. A. A. Saleh, B. M. Eid, N. A. Ibrahim and F. A. Mostafa, Biocatal. Agric.

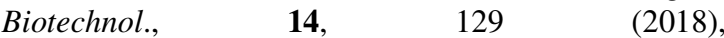
https://doi.org/10.1016/j.bcab.2018.02.011

56 H. Zhang and Q. Sang, Biochem. Eng. J., 97, 101 (2015), https://doi.org/10.1016/j.bej.2015.02.014

57 J. Xue, S. Zhao, R. M. Liang, X. Yin, S. X Jiang et al., Bioresour. Technol., 204, 130 (2016), https://doi.org/10.1016/j.biortech.2015.12.082

58 G. Ramanjaneyulu and B. R. Reddy, Front.

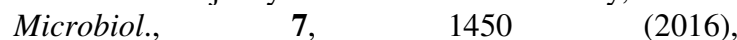
https://doi.org/10.3389/fmicb.2016.01450

59 S. Yegin, Prep. Biochem. Biotechnol., 47, 441 (2017),

https://doi.org/10.1080/10826068.2016.1224245

${ }^{60}$ U. A. Okafor and V. I. Okochi, African J. Biotechnol., $\quad$ 6, $1710 \quad$ (2007), https://www.ajol.info/index.php/ajb/article/view/57761 61 Y. Cao, D. Meng, J. Lu and J. Long, African J. Biotechnol., $\quad 7, \quad 631 \quad$ (2008), https://www.ajol.info/index.php/ajb/article/viewFile/58 $488 / 46832$

${ }^{62}$ S. Yegin, A. Oguz, B. Sayit and S. Yekta, Waste Biomass Valor., $\quad 8, \quad 999 \quad$ (2016), https://doi.org/10.1007/s12649-016-9646-6

63 T. C. dos Santos, N. dos Santos Reis, T. P. Silva, R. C. F. Bonomo, E. Aguiar-Oliveira et al., Waste Biomass Valor., 9, $571 \quad$ (2017), https://doi.org/10.1007/s12649-016-9646-6

${ }^{64}$ T. Carvalho, S. Reis, T. Pereira, J. Rangel and D. O. Marcelo, Waste Biomass Valor., 9, 571 (2017), https://doi.org/10.1007/s12649-016-9810-z

65 S. Pathania, N. Sharma and S. Handa, J. Pharmacogn. Phytochem., 6, 1872 (2017), http://www.phytojournal.com/archives/2017/vol6issue 6/PartZ/6-6-183-481.pdf

66 L. Ping, M. Wang, X. Yuan, F. Cui, D. Huang et al., Int. J. Biol. Macromol., 109, 1270 (2018), https://doi.org/10.1016/j.ijbiomac.2017.11.130

67 E. Rosmine, N. C. Sainjan, R. Silvester, A. Alikkunju and S. A. Varghese, J. Genet. Eng. Biotechnol., $\quad \mathbf{1 5}, \quad 393$ (2017), https://doi.org/10.1016/j.jgeb.2017.06.001

68 M. Hosseinkhani, M. Montazer, S. Eskandarnejad and T. Harifi, J. Nat. Fibers, 14, 175 (2017), https://doi.org/10.1080/15440478.2016.1187702 